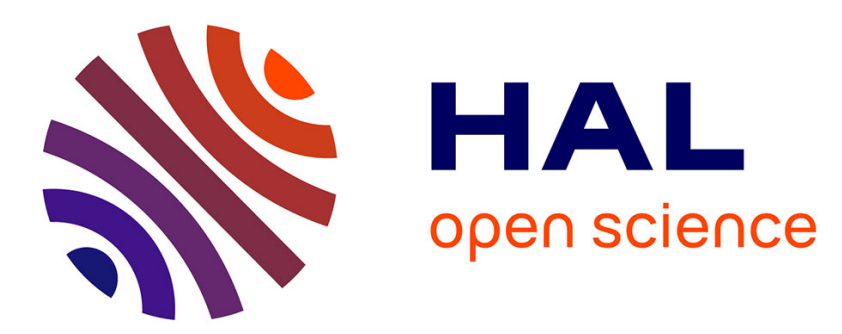

\title{
Computation of the induced current density into the human body due to relative LF magnetic field generated by realistic devices
}

\author{
Riccardo Scorretti, Noël Burais, Olivier Fabrègue, Alain Nicolas, Laurent
} Nicolas

\section{To cite this version:}

Riccardo Scorretti, Noël Burais, Olivier Fabrègue, Alain Nicolas, Laurent Nicolas. Computation of the induced current density into the human body due to relative LF magnetic field generated by realistic devices. IEEE Transactions on Magnetics, 2004, 40 (2 Part 2), pp.643-646. hal-00140336

\section{HAL Id: hal-00140336 https://hal.science/hal-00140336}

Submitted on 6 Apr 2007

HAL is a multi-disciplinary open access archive for the deposit and dissemination of scientific research documents, whether they are published or not. The documents may come from teaching and research institutions in France or abroad, or from public or private research centers.
L'archive ouverte pluridisciplinaire HAL, est destinée au dépôt et à la diffusion de documents scientifiques de niveau recherche, publiés ou non, émanant des établissements d'enseignement et de recherche français ou étrangers, des laboratoires publics ou privés. 


\title{
Computation of the Induced Current Density Into the Human Body Due to Relative LF Magnetic Field Generated by Realistic Devices
}

\author{
Riccardo Scorretti, Noël Burais, Olivier Fabregue, Alain Nicolas, and Laurent Nicolas
}

\begin{abstract}
A three-dimensional finite-element formulation to compute induced currents into the human body due to relative low-frequency magnetic field is described. Magnetic source field and induced currents are computed separately, allowing to handle sources due to realistic devices. This method is validated using analytical solutions over a sphere. The limit of validity of the formulation is established. Computations using an accurate model of the human body are presented.
\end{abstract}

Index Terms-Bioelectric phenomena, dosimetry, quasi-static magnetic fields, three-dimensional (3-D) finite-element methods.

\section{INTRODUCTION}

$\mathbf{T}$ HE DAILY exposure to an electromagnetic environment raises the question of the effects of relative low-frequency (up to $1 \mathrm{MHz}$ ) magnetic fields on human health. The accurate assessment of the currents induced in the human body by a time-varying magnetic field is a major issue, not only for its relevance in medical research, but also for its implications on the definition of industrial standards [1]. Using the results of epidemiological studies and by application of the principle of "as low as reasonably achievable" (ALARA), the governments have imposed some limitations to the authorized radiated fields by the power systems. In the case of the low-frequency magnetic fields, these limitations have been defined on the basis of the induced current density in the human body. That is, a set of maximum values of current density have been defined. These values are called basic restrictions and should not be exceeded in any case. On the basis of these restrictions, some reference levels for the magnetic field have been defined, as a function of the frequency. The magnetic field is allowed to exceed these reference levels, provided that the basic restrictions on the current density are respected. These reference levels have been obtained using computational techniques performed on very simple models. Generally, both the magnetic source and the geometric model of the human body are considered to be very simple. Thus, the current density may be overestimated [2]. A better knowledge of the way the current density develops inside the human body would allow the assessment of more acceptable limits for the radiated fields.

Manuscript received July 1, 2003. This work was supported in part by Electricité de France (EDF)—Division R\&D—Groupe Compatibilité Electromagnétique.

The authors are with the Ecole Centrale de Lyon, 69134 Ecully, France.

Digital Object Identifier 10.1109/TMAG.2004.825436
TABLE I

Conductivities of Usual Human Tissues

\begin{tabular}{llllll}
\hline \hline & $10 \mathrm{~Hz}$ & $1 \mathrm{kHz}$ & $10 \mathrm{kHz}$ & $100 \mathrm{kHz}$ & $1 \mathrm{MHz}$ \\
\hline Fat & 0.012207 & 0.022404 & 0.02383 & 0.024414 & 0.025079 \\
Muscle & 0.20197 & 0.32115 & 0.34083 & 0.36185 & 0.50268 \\
Bone & 0.075563 & 0.08153 & 0.02043 & 0.083892 & 0.024353 \\
Kidney & 0.05441 & 0.11274 & 0.13774 & 0.17134 & 0.27823 \\
Liver & 0.027714 & 0.04138 & 0.053495 & 0.084568 & 0.18665 \\
Blood & 0.7 & 0.7 & 0.70004 & 0.70292 & 0.82211 \\
Intestine & 0.51113 & 0.53236 & 0.55967 & 0.5942 & 0.86488 \\
Bladder & 0.20278 & 0.20758 & 0.21303 & 0.2189 & 0.23608 \\
\hline \hline
\end{tabular}

\section{A. Electric Properties of the Living Systems}

The computation of electromagnetic quantities in the human body is a difficult challenge, in that the particularities of this "system" have to be taken into account [3], [4]. First, the human body has a highly heterogeneous structure, which results into a very complicated geometry. Most importantly, it does not exist in a characteristic scale: the structure of the human body is completely different at the cell scale, at the tissue scale, or at the scale of the whole body. The electric properties of the human body are very unusual and are still not well known, compared to those of classical electric systems. These properties have been intensely investigated during the last decades [5]-[9] and have been proven to depend upon several parameters, and notably upon the frequency and the activity of the person. Moreover, these properties cannot be measured in vivo. The electrical permittivity $\varepsilon_{r}$ is exceptionally high at low frequencies (for instance, the permittivity of the blood is $\varepsilon_{r}=4.35 \cdot 10^{5}$ at $1 \mathrm{kHz}$ ), and decreases with the frequency.

The values of the conductivity $\sigma$ for several tissues are tabulated in Table I at different frequencies. One observes that these values are very low, compared to the "usual" conductor materials ( $\sigma=10^{6} \mathrm{~S} / \mathrm{m}$ for the copper). On the other hand, the permeability $\mu_{r}$ of the human body is 1 .

\section{B. Choice of the Method}

Our purpose is to compute accurately the currents induced into the human body by realistic devices, such as transformers, motors, or electronic article surveillance devices. Indeed, other works already exist on the computation of induced currents into the human body using different methods like finite-element (FE) [10], [11], finite-difference time-domain (FDTD) [12], or impedance method (IM) [13]. In most of these works, great attention is paid to the model of the human body. As example, in [14], a model composed of about 379 million voxel cells has been used, together with an FD-type method. On the other 
TABLE II

SKIN DEPTH (IN METERS) FOR USUAL HUMAN TISSUES

\begin{tabular}{llllll}
\hline \hline & $10 \mathrm{~Hz}$ & $1 \mathrm{kHz}$ & $10 \mathrm{kHz}$ & $100 \mathrm{kHz}$ & $1 \mathrm{MHz}$ \\
\hline Fat & $1440 \mathrm{~m}$ & 106 & 32 & 10 & 3.2 \\
Muscle & 354 & 28 & 8.6 & 2.6 & 0.7 \\
Bone & 579 & 56 & 35 & 5.5 & 3.2 \\
Kidney & 682 & 48 & 14 & 3.8 & 0.9 \\
Liver & 956 & 78 & 22 & 5.4 & 1.1 \\
Blood & 190 & 19 & 6 & 1.9 & 0.6 \\
Intestine & 222 & 22 & 7 & 2.1 & 0.5 \\
Bladder & 353 & 35 & 11 & 3.4 & 1.0 \\
\hline \hline
\end{tabular}
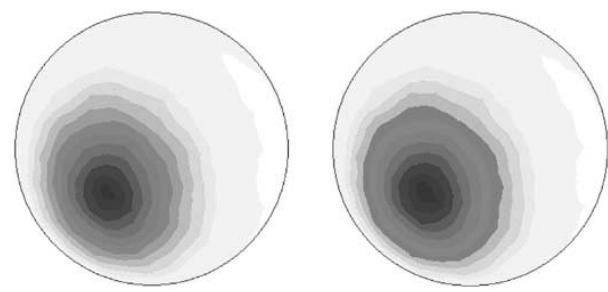

Fig. 1. Magnitude of the electric field on the sphere $(f=100 \mathrm{kHz}, \sigma=1$, $\mu_{r}=1, a=0.1 \mathrm{~m}$ ). (Left) Analytical solution. (Right) numerical solution (2982 nodes).

hand, the sources of the magnetic field are generally quite simple: the field is often supposed to be uniform or at most generated by a wire system [12]. However, in proximity to an electrical device, the magnetic field is far more complicated. At the same time, the region close to the device is precisely the region where the field is more intense. Thus, when the purpose is to assess the values of the current density induced by a realistic device into the human body, the magnetic field has to be modeled accurately.

In this paper, a special three-dimensional (3-D) FE formulation based on a quasi-static A- $\phi$ formulation is presented. The interest of this formulation is that it allows to compute separately the magnetic field generated by the electrical device, and the induced currents into the human body. The choice to implement the FE method comes from the fact that the tetrahedral elements allow a good representation of complicated geometries, even with a moderate number of elements.

The model of the human body that has been adopted is compatible with the typical skin-depth of the tissues (Table II) at the given frequencies. On the other hand, at present time, any model of the human body is intrinsically limited by the incertitude on the electrical parameters, and by the anatomical differences between different persons. Thus, in the author's opinion, it is a matter of discussion whether the use of a model with a higher resolution really leads to a better knowledge.

\section{FORMULATION}

Let $\Omega$ the region occupied by the human body, and $\Gamma$ its boundary. For the considered range of frequencies (up to $1 \mathrm{MHz}$ ), the wavelength of the electromagnetic field is much larger than the human body (300 $\mathrm{m}$ at $1 \mathrm{MHz})$, thus a quasi-static approach is used. The permittivity of the human body is exceptionally high. Thus, it is a matter of discussion whether the displacement currents are negligible [4], [11]. In
TABLE III

ERror CRITERION DEPENDING ON THE MEsh Size

\begin{tabular}{ccccc}
\hline \hline $\begin{array}{c}\text { Number of } \\
\text { surface } \\
\text { points }\end{array}$ & $\begin{array}{c}\text { Number of } \\
\text { nodes }\end{array}$ & $\begin{array}{c}\text { Number of } \\
\text { elements }\end{array}$ & $\begin{array}{c}\text { Error on } \\
\text { potential }\end{array}$ & $\begin{array}{c}\text { Error on } \\
\text { magnitude of } \\
\text { the field }\end{array}$ \\
\hline 100 & 132 & 427 & $2.31 \%$ & $3.81 \%$ \\
200 & 229 & 651 & $2.86 \%$ & $3.99 \%$ \\
400 & 510 & 1676 & $1.64 \%$ & $2.28 \%$ \\
500 & 1775 & 9075 & $0.45 \%$ & $2.20 \%$ \\
850 & 2982 & 15309 & $0.38 \%$ & $1.75 \%$ \\
\hline \hline
\end{tabular}

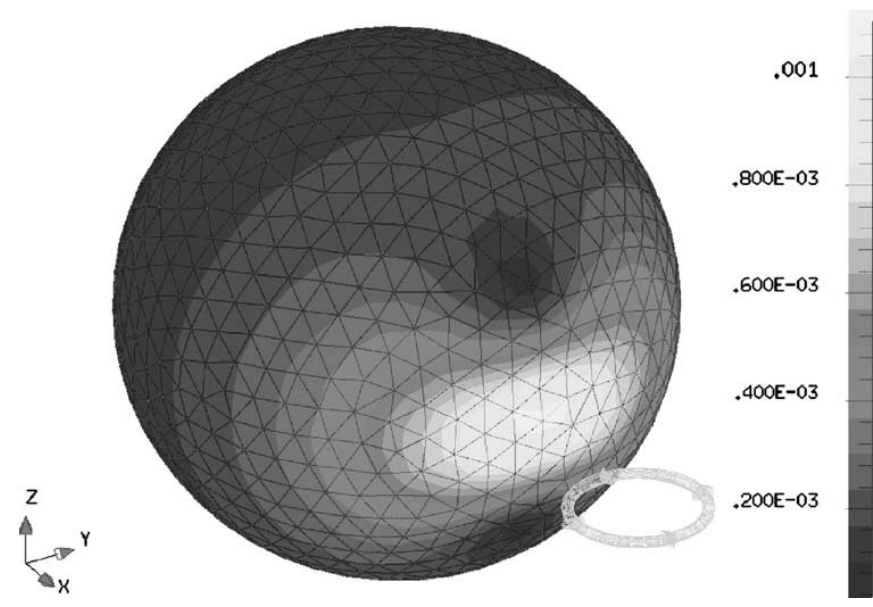

Fig. 2. Magnitude of the electric field on the sphere ( $f=100 \mathrm{kHz}, \sigma=1$, $\mu_{r}=1, a=0.1 \mathrm{~m}$ ) induced by a circular coil.

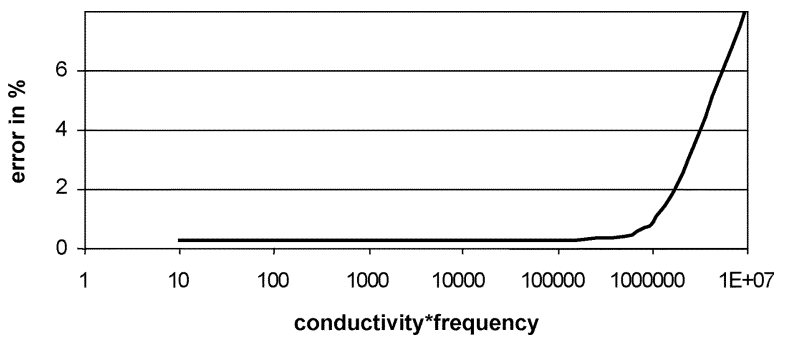

Fig. 3. Comparison with a general formulation: error criterion depending on the product $\sigma f$.

this paper, it is supposed that actually they are. Under these assumptions, the curl of the electric field $\vec{E}$ can be written as

$$
\vec{\nabla} \times \vec{E}=-j \omega \vec{\nabla} \times \vec{A}
$$

where $\vec{A}$ is the magnetic vector potential. Thus, the electric field $\vec{E}$ can be expressed by

$$
\vec{E}=-j \omega \vec{A}-\vec{\nabla} \phi
$$

where $\phi$ is an electric scalar potential. By using the Ohm's law the induced current density $\vec{J}$ can be written as

$$
\vec{J}=-\sigma(j \omega \vec{A}+\vec{\nabla} \phi) .
$$

As the conductivity values of the human body are low (Table I), it can be assumed that the magnetic field is not modified in an appreciable way by the induced currents in the human body [4], [10]-[13]. Hence, the vector potential $\vec{A}$ in (3) corresponds to the magnetic field generated by the appliance in free space. This potential is assumed to be known: either it can be obtained from analytical or numerical computations, 

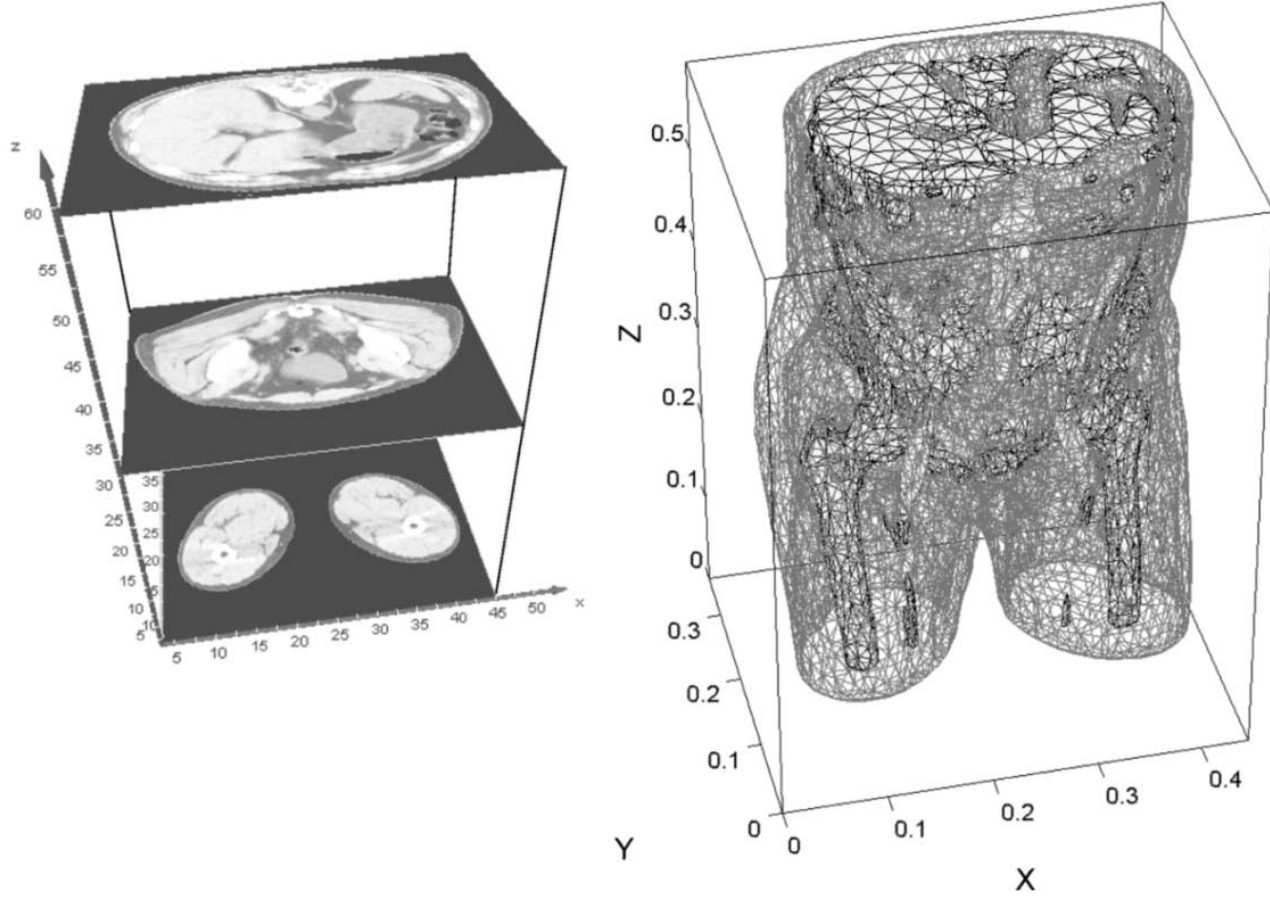

Fig. 4. CT scans and mesh of the model of the human body.

or it can be identified from experimental measurements. By replacing (3) in the charge conservation equation $\vec{\nabla} \cdot \vec{J}=0$ one finds

$$
\vec{\nabla} \cdot(\sigma \vec{\nabla} \phi)=-j \omega \vec{\nabla} \cdot(\sigma \vec{A})
$$

In this equation, the scalar potential $\phi$ is the unknown, and the vector potential $\vec{A}$ is the source term. Equation (4) holds everywhere inside the volume $\Omega$, provided that the divergence operator is defined in the sense of the distribution's theory. However, a special attention must be paid to the interfaces between two regions $\Omega_{1}$ and $\Omega_{2}$ with different conductivities. In these points the current density $\vec{J}$ is actually not continuous, and the continuity of its normal component has to be ensured

$$
\left(\overrightarrow{J_{1}}-\overrightarrow{J_{2}}\right) \cdot \vec{n}=0 \text {. }
$$

Notably, at the boundary of the human body $\Gamma$ the normal component of $\vec{J}$ is zero, that is the current cannot spread out of the body. Hence, the boundary conditions are

$$
\frac{\partial \phi}{\partial n}=-j \omega \vec{A} \cdot \vec{n}
$$

Equations (4)-(6) represent the strong formulation of the problem. Now, let $w: \Omega \mapsto \mathbb{C}$ be a continuous, piecewise differentiable function. By multiplying each member of (4) by $w$, and after integration by parts over $\Omega$, one finds

$$
\iiint_{\Omega} \sigma \vec{\nabla} \phi \cdot \vec{\nabla} w d \Omega=-\iiint_{\Omega} j \sigma \omega \vec{A} \cdot \vec{\nabla} w d \Omega .
$$

It can be shown that there exists only one function $\phi$ such that (7) holds for any continuous, piecewise differentiable function. Moreover, this function is precisely the solution of (4)-(6). It is worthful to remark that the scalar potential $\phi$ is a continuous, piecewise differentiable variable. The conductivity $\sigma$ is a scalar piecewise continuous variable, thus the potential $\phi$ scales linearly with the frequency $\omega$, and with the source term $\vec{A}$. At present time, the anisotropy of the tissues is not taken into account. The problem to find the function $\phi$ such that (7) holds for any $w$ is a weak formulation of the problem (4)-(6).

This problem is computed with the FE method with classical nodal elements [15], in that the unknown potential $\phi$ is continuous. The conjugate gradient method is used to solve the linear system. There are two main advantages to such a formulation, compared to a general one. First, the induced currents are computed separately from the magnetic source field: it is then possible to use accurate geometric models for both the magnetic source device and the human body. Second, conductivities of the human tissues (Table I) are not of the same order than those of the electrical devices, leading to ill-conditioned matrices. By decoupling both problems - the magnetic vector potential due to the source, and the induced currents into the human body—better solving may be obtained.

\section{VALIDATION}

The numerical method has been validated by comparing the results with both analytical and numerical solutions.

\section{A. Comparison With Analytical Solutions}

Under the same assumptions used to develop the FE formulation (propagation effects, displacement currents and the "armature reaction" are neglected), some "exact" analytical solutions can be obtained in the case of a sphere [16]. For the case of a field gradient along the $z$ axis $\vec{B}=G_{Z} z \vec{e}_{z}$ one finds for the electric field

$$
\vec{E}=-\frac{j \omega}{4} G_{Z} r^{2} \sin (2 \vartheta) \vec{e}_{\varphi}
$$


The numerical and analytical solutions have been compared on the basis of the criterion error

$$
\chi[\vec{E}]=\frac{1}{V \cdot \max \left\|\vec{E}_{\mathrm{FE}}\right\|} \iiint_{\Omega}\left\|\vec{E}_{\mathrm{FE}}-\vec{E}_{\mathrm{an}}\right\| d \Omega
$$

where $\vec{E}_{\mathrm{FE}}$ is the FE solution, and $\vec{E}_{\mathrm{an}}$ is the analytical electric field. As shown in Table III, a good agreement is found. The numerical solution converges toward the exact one when the mesh size is reduced.

\section{B. Comparison With a Numerical Solution}

Then, the formulation has been checked by comparing the results with those obtained using a general formulation, computed with the Flux 3D package (2D/3-D FEM Software Products Developed by INPG/LEG and CEDRAT). A classical quasi-magnetoharmonic formulation $T-\phi-\phi_{\text {red }}$ has been used: propagation effects and displacement currents are neglected, but the "armature reaction" is taken into account. The electric field induced in a sphere by a circular coil (Fig. 2) is computed for different values of the product $\sigma f$, where $\sigma$ is the conductivity and $f$ is the frequency of the source currents. The sphere is meshed using 15309 tetrahedral elements of the second order. Fig. 3 shows that the threshold of validity of the formulation is found in the range $10<\sigma f<10^{7} \Omega^{-1} \cdot \mathrm{s}^{-1} \cdot \mathrm{m}^{-1}$. From the values of conductivity of the human tissues (Table I), it is then seen that the two formulations are equivalent in the $10-\mathrm{Hz}$ to $1-\mathrm{MHz}$ range. This validates the assumption that the magnetic field is not modified in an appreciable way by the induced currents in the human body.

\section{APPLiCATIONS}

The method is used together with an anatomical model of the human body. The mesh is obtained from 59 CT scans, allowing to take into account the real shape of the human body (Fig. 4). It has been obtained using the Amira package (Amira-Template Graphics Software Inc.). ${ }^{1}$ It is made of 33181 nodes and 182650 tetrahedral elements, leading to 221606 degrees of freedom. This geometry includes 11 different media.

The vector potential can be obtained either from analytical computation, or from a separate numerical FE computation, or it can be obtained from experimental data by modeling the device with a multipole [17].

As qualitative example, the currents induced in a human body by an AC motor-like structure are computed. The vector magnetic potential is computed separately using the Flux 3D package. Two orientations of the motor are compared. The axis of the motor is first located vertically (Fig. 5, left). Second, the rotor is rotated toward the human body (Fig. 5, right) in such a way that the distances are unchanged. It is observed that in the first case the induced currents are larger due to the flux leakage.

\section{CONCLUSION}

A method to compute the currents induced by realistic devices in the human body is presented. The results obtained allows to study the influence of the parameters of radiating devices on

\footnotetext{
${ }^{1}$ http://www.amiravis.com
}
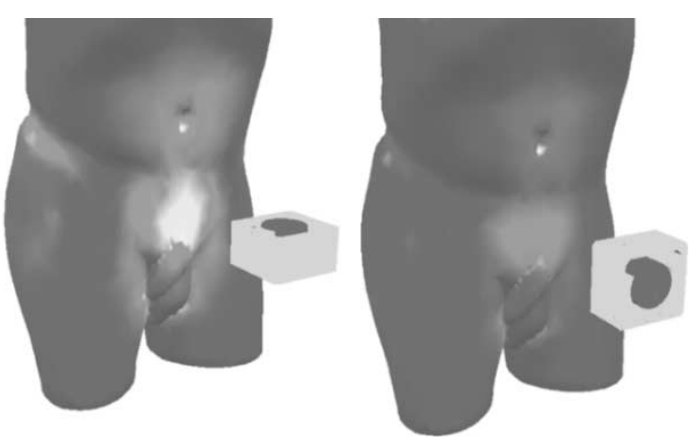

Fig. 5. Current density induced in the human body by a DC motor.

induced currents. This knowledge is useful in order to search simplified models of appliances, which aim to catch the features of the stray field that are sole essential to compute accurately the induced currents in the human body.

\section{REFERENCES}

[1] ICNIRP, "Guidelines for limiting exposure to time-varying electric, magnetic and electromagnetic fields (up to $300 \mathrm{GHz}$ )," Health Phys., vol. 74, no. 4, pp. 494-522, 1998.

[2] N. Burais, P. Baraton, and J. Y. Gaspard, "Modélization numérique des courants induits dans le corps humain par des dispositifs électromagnétiques dans la gamme des fréquences intermédiaires," in Proc. 9th Colloque Int. CEM, 1998.

[3] N. Siauve, R. Scorretti, N. Burais, L. Nicolas, and A. Nicolas, "Electromagnetic fields and human body: A new challenge for the electromagnetic field computation," Compel, vol. 22, no. 3, pp. 457-469, 2003.

[4] L. Nicolas, N. Burais, C. Poignard, R. Scorretti, and N. Siauve, "Interactions between electromagnetic fields and biological tissues: questions, answers and future trends," ICS Newslett., vol. 10, no. 2, pp. 4-9, 2003.

[5] H. P. Schwan, "Electric characteristics of tissues," Biophysik, vol. 1, pp. 198-208, 1963

[6] M. A. Stuchly and S. S. Stuchly, "Dielectric properties of biological substances-tabulated," J. Microwave Power, vol. 15, no. 1, pp. 19-26, 1980.

[7] C. Gabriel, S. Gabriel, and E. Corthout, "The dielectric properties of biological tissues: I. Literature," Phys. Med. Biol., vol. 41, pp. 2231-2249, 1996.

[8] S. Gabriel, R. W. Lau, and C. Gabriel, "The dielectric properties of biological tissues: II. Measurements in the frequency range $10 \mathrm{~Hz}$ to 20 GHz," Phys. Med. Biol., vol. 41, pp. 2251-2269, 1996.

[9] — - "The dielectric properties of biological tissues: III. Parametric models for the dielectric spectrum of tissues," Phys. Med. Biol., vol. 41, pp. 2271-2293, 1996.

[10] G. A. Mouchawar, J. A. Nyenhuis, J. D. Bourland, L. A. Geddes, D. J. Schaefer, and M. E. Riehl, "Magnetic stimulation of excitable tissue: calculation of induced eddy-currents with a three-dimensional finite-element model," IEEE Trans. Magn., vol. 29, Nov. 1993.

[11] W. Wang and S. R. Eisenberg, "A three-dimensional finite element method for computing magnetically induced currents in tissues," IEEE Trans. Magn., vol. 30, Nov. 1994.

[12] T. W. Dawson, K. Caputa, and M. A. Stuchly, "Organ dosimetry for human exposure to nonuniform $60-\mathrm{Hz}$ magnetic fields," IEEE Trans. Power Del., vol. 14, Oct. 1999.

[13] N. Hayashi, K. Isaka, H. Tarao, and Y. Yokoi, "Numerical calculation of induced electric field and currents on simple models of multi-medium biological systems using the impedance method," in Proc. 9th Int. Symp. High Voltage Engineering, Graz, Austria, 1995.

[14] F. Sachse, Modelle des menschlichen Körpers zur Berechnnug von physikalischen Felder. Berlin, Germany: Shaker-Verlag.

[15] T. J. R. Huges, The Finite Element Method. New York: Dover, 2000.

[16] M. Bencsik, R. Botwell, and R. M. Bowley, "Electric fields induced in a spherical volume conductor by temporally varying magnetic field gradients," Phys. Med. Biol., vol. 47, pp. 557-576, 2002.

[17] R. Scorretti, R. Takahashi, L. Nicolas, and N. Burais, "Optimal characterization of LF magnetic field using multipoles," in Proc. EMF Conf., 2003. 